\title{
Regional Lymphotropic Therapy in Combination with Low Level Laser Therapy for Treating Multi-Drug-Resistant Tuberculosis
}

\author{
Oksana Dogorova; Ekaterina Pavlova, PhD*; Maria Vinokurova, PhD, ScD \\ Republic Research-and-Practice Center for Tuberculosis \\ Yakutsk, the Republic of Sakha, Russia
}

\begin{abstract}
With the growing incidence of Multi-Drug-Resistant Tuberculosis (MDR-TB) in newly identified patients, novel multimodality treatment methods are needed, aimed at reducing the time to sputum conversion and cavity healing, which would be applicable in MDR cases.

Our experimental treatment consisted of the following: 1) chemotherapy based on the drug sensitivity profile, 2) local laser irradiation therapy for 25 days, and lymphotropic administration of isoniazid (to subcutaneous tissue in alternating locations: underarm area; fifth intercostal space along the sterna border; subclavian area where the first rib meets the sternum) in a daily dose of $10 \mathrm{mg} / \mathrm{kg} 5$ times a week. This treatment was significantly more effective in newly detected destructive MDR-TB versus the standard Category IV regimen for MDR-TB in terms of reduced time for sputum culture conversion and cavity healing, estimated to be 6 months after initiation of treatment. (Int J Biomed. 2016; 6(1):82-84.).
\end{abstract}

Keywords: multi-drug-resistant tuberculosis; laser irradiation therapy; lymphotropic therapy; isoniazid.

\section{Introduction}

WHO estimated 9 million new tuberculosis (TB) cases and 1.5 million TB deaths in 2013. Globally, 480,000 MDR-TB cases were noted [1]. Despite the introduction of combination regimens throughout the world many years ago, the presence of drug resistance has been progressively documented in an ever wider geographical area [2]. Recent estimates by WHO suggest that nearly half a million cases of MDR-TB (defined as tuberculosis caused by strains of Mycobacterium tuberculosis that are resistant to at least isoniazid and rifampicin, the 2 most powerful first-line anti-TB drugs) emerged globally in 2008 [3]. MDR-TB cases are difficult to treat and have high mortality. M.K.Vimokurova et al. [4] have observed in the Sakha Republic (Yakutia) a growth in the incidence of TB cases presenting with destructions in lung tissue and a bacillary-positive state, a persistent trend towards an increase in TB cases caused by MDR MTB, and a high proportion of deaths during the first year of outpatient follow-up for TB. Many experts feel that high-dose isoniazid can be used against strains resistant to low concentrations of isoniazid but

*Corresponding author: Ekaterina Pavlova, PhD. Republic Research-and-Practice Center for Tuberculosis, Yakutsk, the Russian Federation.E-mail: esp71@mail.ru susceptible to higher doses [5] ( $>1 \%$ of bacilli resistant to 0.2 $\mathrm{mcg} / \mathrm{ml}$ but susceptible to $1 \mathrm{mcg} / \mathrm{ml}$ of isoniazid), whereas, isoniazid is not recommended for high-dose resistance $(>1 \%$ of bacilli resistant to $1 \mathrm{mcg} / \mathrm{ml}$ of isoniazid). Some experts give $900 \mathrm{mg}$ three times a week [6] in adults while others use as high as $16-20 \mathrm{mg} / \mathrm{kg} /$ day [7]. Good data are not available on the safety of high-dose isoniazid, and there may be possible associated higher rates of peripheral neuropathy, hepatitis, and other unforeseen adverse effects [8].

Isoniazid metabolism is known to be impacted by genetic factors [9]. This in turn could have important clinical implications in terms of therapeutic efficacy and occurrence of adverse events. Isoniazid is metabolized by acetylation; this conjugation reaction is catalyzed by NAT2. Several studies over the years have shown that human subjects show a wide degree of variation in their capacity to acetylate or inactivate isoniazid to acetyl isoniazid. NAT2 genotyping prior to isoniazid administration would help clinicians in predicting pharmacokinetic variability, and adjusting the isoniazid dose.

The relationship between ethnicity, genetic background, and response to tuberculosis treatment has not been well studied. In the studies by S.S. Gavriliev et al. [10], it was found that slow acetylators of isoniazid prevail among the population of Yakutia.

The method of regional lymphotropic therapy (RLTT), 
which is characterized by drug administration into the lymphatic system, has been known for more than 30 years. Laser irradiation (low-level laser therapy) has been used as an adjuvant to anti-tubercular drugs in cases of chronic drug resistant pulmonary tuberculosis for several years [1,10-12].

The aim of this study was to develop a treatment method for MDR-TB based on laser-assisted lymphotropic administration of isoniazid in combination with the standard Category IV regimen.

\section{Material and Methods}

Ninety-one patients with newly diagnosed destructive infiltrative pulmonary MDR-TB were included in the study, all HIV-negative. Resistance to isoniazid was assessed as low $(1 \mathrm{mkg} / \mathrm{mg})$ in all patients; isoniazid acetylation type was either slow or moderate. All patients (except pregnant women) received hospital-based treatment at the Department for Pulmonary MDR-TB of the Research-and-Practice Center for TB, from 2011 to 2013.

We employed conventional examination methods, which included physical examination, clinical laboratory tests, X-ray and tomographic exams, sputum culture test with simultaneous drug sensitivity determination by absolute concentration method, using solid Lowenstein-Jensen medium; isoniazid activity was assessed by Wollenberg-Grebennik method (1961), and prescribed anti-tuberculosis treatment based on drug sensitivity profiles and in compliance with the RF MOH Order no.109 [13].

The control group included 44 patients who received an intensive phase of standard Category IV chemotherapy regimen for MDR-TB based on drug sensitivity profiles.

The experimental group included 47 patients who received the experimental treatment method, which included a lymphotropic isoniazid administration coupled with laser irradiation on the background of standard Category IV chemotherapy regimen for MDR-TB. Contraindications to the experimental treatment were: 1) individual intolerance to substances, pyoinflammatory diseases of the skin and subcutaneous tissue, severe pain syndrome developing in response to administration of medicinal substances; and 2) pulmonary hemorrhages and hemoptysis, pronounced cardiopulmonary insufficiency, neoplasms, organic brain lesions, II-III degree thyrotoxicosis, DM decompensation, pregnancy, and diseases of the blood.

Isoniazid, known as a highly lymphotropic agent, possesses great potential to enter and reversibly bind with the cell structures of the lymphatic system. To ensure the entry of isoniazid into the lymphatic stream, its administration is preceded by the introduction of a drug carrier and lymphstimulating agent, heparin $(1 \mathrm{ml}=5000 \mathrm{IU})$, diluted in $4 \mathrm{~mL}$ of Novocaine solution $0.5 \%$. The daily dose of isoniazid solution $(10 \mathrm{mg} / \mathrm{kg})$ is administered to subcutaneous tissue, right after the injection of heparin, using the same needle. It is important, that the injection locations must alternate each day. The injection site is immediately exposed to laser irradiation. Treatment is administered 5 times a week, for 25 days. The procedure is performed in the procedure room, in strict compliance with the aseptic and antiseptic regulations. On weekends and after the end of the laser-assisted RLTT course, isoniazid was administered in the morning (10 a.m.), intramuscularly, a daily dose of $10 \mathrm{mg} / \mathrm{kg}$. Twenty-one days after the end of laser-assisted RLTT course, X-ray and CT checks were performed. Based on the findings, a doctor can assign a repeated treatment course.

Statistical analysis was performed using the SPSS for Windows. Baseline characteristics were summarized as frequencies and percentages for categorical variables. Group comparisons with respect to categorical variables are performed using chi-square tests or, alternatively, Fisher's exact test when expected cell counts were less than 5. A probability value of $P<0.05$ was considered statistically significant.

The study was conducted in accordance with ethical principles of the Declaration of Helsinki and approved by the Republic Research-and-Practice Center for Tuberculosis Ethics Committee. Written informed consent was obtained from all participants.

\section{Results and Discussion}

Patients of both groups were matched by age and sex, pulmonary disease duration and predominance of cases with disseminated TB involving 2 or more lobes, sizes of destructions in lung tissue, and a primary MDR profile (Table 1).

Table 1.

Mycobacterium tuberculosis the primary MDR profiles

\begin{tabular}{|l|c|c|c|c|c|c|}
\hline \multirow{2}{*}{ Drug combinations } & \multicolumn{2}{|c|}{$\begin{array}{c}\mathrm{EG} \\
\mathrm{n}=47\end{array}$} & \multicolumn{2}{c|}{$\begin{array}{c}\mathrm{CG} \\
\mathrm{n}=44\end{array}$} & \multicolumn{2}{c|}{$\begin{array}{c}\text { Total } \\
\mathrm{n}=91\end{array}$} \\
\cline { 2 - 7 } & $\begin{array}{c}\text { Abs. } \\
\text { number }\end{array}$ & $\begin{array}{c}\text { Abs. } \\
\text { number }\end{array}$ & $\begin{array}{c}\text { Abs. } \\
\text { number }\end{array}$ & $\%$ \\
\hline $\mathrm{HR}$ & 2 & 4.3 & 1 & 2.3 & 3 & 3.3 \\
\hline $\mathrm{HR} / \mathrm{S} / \mathrm{E}$ & 23 & 48.9 & 26 & 59.1 & 49 & 53.9 \\
\hline $\mathrm{HRSKm} / \mathrm{Cm} / \mathrm{E} / \mathrm{PAS} / \mathrm{Et} / \mathrm{Cs}$ & 17 & 36.2 & 14 & 31.8 & 31 & 34 \\
\hline $\mathrm{HRSOf} / \mathrm{E} / \mathrm{Et}$ & 5 & 10.6 & 3 & 6.8 & 8 & 8.8 \\
\hline
\end{tabular}

$H$-isoniazid; $R$-rifampicin; $S$-streptomycin; Km-kanamycin; E-ethambutol; Cm-capreomycin; Et-ethionamide; PAS-paraamynosalicilic acid; Of-ofloxacine; EG - Experimental group;

$C G$ - Control group

After 6 months of chemotherapy, sputum culture conversion was observed in $41 / 87.3 \%$ patients of the experimental group versus $25 / 56.2 \%$ patients in the control group $(P=0.02)$. X-ray and tomographic examinations after 6 months of chemotherapy showed cavity closures in $29 / 62.9 \%$ patients in the experimental group and in $17 / 38.7 \%$ patients in the control group $(P=0.007)$. Differences between the experimental and control groups, in terms of sputum culture conversion and radiological cavity closure, were statistically significant (Table 2).

The developed method of regional lymphotropic isoniazid administration in combination with laser irradiation on top of an intensive phase of regimen IV for MDR-TB significantly improved treatment effectiveness in newly 
detected destructive TB patients with low resistance to isoniazid and a slow or moderate isoniazid acetylation type, resulting in a 1.5 times faster sputum culture conversion and 1.6 times faster cavity healing.

\section{Table 2.}

Effectiveness of regional lymphotropic isoniazid administration in combination with laser irradiation in newly detected destructive MDR-TB patients

\begin{tabular}{|l|c|c|c|c|}
\hline \multirow{2}{*}{ Study groups } & \multicolumn{2}{|c|}{$\begin{array}{c}\text { Sputum culture } \\
\text { conversion after 6 } \\
\text { months of therapy }\end{array}$} & \multicolumn{2}{c|}{$\begin{array}{c}\text { Radiological cavity } \\
\text { closure after 6 months } \\
\text { of therapy }\end{array}$} \\
\cline { 2 - 5 } & Abs. number & $\%$ & Abs. number & $\%$ \\
\hline Experimental group & 41 & 87.2 & 29 & 61.7 \\
\hline Control group & 25 & 56.8 & 17 & 38.6 \\
\hline & \multicolumn{2}{|c|}{$\begin{array}{l}\chi^{2}=10.551 \\
P=0.0026\end{array}$} & \multicolumn{2}{|c|}{$\begin{array}{c}\chi^{2}=4.837 \\
P=0.0466\end{array}$} \\
\hline
\end{tabular}

The developed method can be adopted by specialized tuberculosis clinics and requires only conventional equipment commonly used in procedure and laser therapy rooms.

\section{Competing interests}

The authors declare that they have no competing interests.

\section{References}

1. Bhagwanani NS1, Bhatia CC1, Sharma N1, Hemvani N1, Chitnis DS1.Low level nitrogen laser therapy in pulmonary tuberculosis.Laser Ther. 2015;24(3):209-14.

2. Wright A, Zignol M, Van Deun A, Falzon D, Gerdes SR, Feldman K,, et al.; Global Project on Anti-Tuberculosis Drug Resistance Surveillance. Epidemiology of antituberculosis drug resistance 2002-07: an updated analysis of the Global Project on Anti-Tuberculosis Drug Resistance Surveillance. Lancet 2009; 373(9678):1861-73.
3. World Health Organization (WHO). Multidrug and extensively drug-resistant TB (M/XDR-TB): 2010 global report on surveillance and response. Geneva, Switzerland: WHO, 2010. (WHO/HTM/TB/2010.3).

4. Vinokurova MK, Alexandrov VL, Yakovleva LP, Oshchepkova NM. Trends in the development of the epidemiological situation of tuberculosis in the Republic Sakha (Yakutia) in 2004-2011. YAKUT MEDICAL JOURNAL. 2013;(1):58-63. [Article in Russian].

5. Katiyar SK, Bihari S, Prakash S, Mamtani M, Kulkarni H. A randomised controlled trial of high-dose isoniazid adjuvant therapy for multidrug-resistant tuberculosis. Int J Tuberc Lung Dis. 2008;12(2):139-45. [PubMed]

6. PIH guide to medical management of multidrug-resistant tuberculosis. Boston: Partners in Health; 2003. [15 March 2014]. http://www.pih.org/publications/entry/pih-guide-tothe-medical-management-of-multidrug-resistant-tuberculosis/ 7. Rom WN, Garay SM, editors. Tuberculosis. Philadelphia: Lippincott Williams \& Wilkins; 2004.

8. Companion Handbook to the WHO Guidelines for the Programmatic Management of Drug-Resistant Tuberculosis. WHO Guidelines Approved by the Guidelines Review Committee. Geneva: World Health Organization; 2014.

9. Ramachandran G, Swaminathan S. Role of pharmacogenomics in the treatment of tuberculosis: a review. Pharmgenomics Pers Med. 2012; 5:89-98.

10. Gavriliev SS, Vinokurova MK, Illarionov TS. Individualized chemotherapy for pulmonary tuberculosis. Yakutsk; 2003. [in Russian].

11. Gavriliev SS, Vinokurova MK, Mordovskaya LI. Semiconductor lasers for phthisiatry. New treatment technology. Novosibirsk; 2004. [in Russian].

12. Puri MM, Arora VK. Role of gallium arsenide laser irradiation at $890 \mathrm{~nm}$ as an adjunctive to anti-tuberculosis drugs in the treatment of pulmonary tuberculosis.Indian $\mathrm{J}$ Chest Dis Allied Sci. 2003; 45(1):19-23.

13. MOH. Ministry of Health and Social Development of the Russian Federation. Order No 109 "On the improvement of TB control activities in the Russian Federation"; 2003. Available from: www.consultant.ru/document/cons_doc_ LAW_100873/ 